\title{
Monitoring magnesium degradation using microdialysis and fabric-based biosensors
}

\author{
M. Su Natasha ${ }^{1 \dagger}$, Radha S. P. Malon ${ }^{1,2 \dagger}$, Dedy H. B. Wicaksono ${ }^{1,3}$, Emma P. Córcoles $^{1,4}$ and \\ Hendra Hermawan ${ }^{1,5^{*}}$
}

\begin{abstract}
This paper describes the development of a monitoring system capable of detecting the concentration of magnesium ions $\left(\mathrm{Mg}^{2+}\right)$ released during the degradation of magnesium implants. The system consists of a microdialysis probe that samples fluid adjacent to the implant and a catalytic biosensor specific to $\mathrm{Mg}^{2+}$ ions. The biosensor was fabricated on a cotton fabric platform, in which a mixture of glycerol kinase and glycerol-3-phosphate oxidase enzymes was immobilized on the fabric device via a simple matrix entrapment technique of the cotton fibers. Pure magnesium was used as the implant material. Subsequently, the concentration of ions released from the degradation of the magnesium specimen in Ringer's solution was evaluated using cyclic voltammetry technique. The device demonstrated a pseudo-linear response from 0.005 to $0.1 \mathrm{mmol} \mathrm{L}^{-1}$ with a slope of $67.48 \mu \mathrm{A}$ $\mathrm{mmol}^{-1} \mathrm{~L}$. Detectable interfering species were lesser than $1 \%$ indicating a high selectivity of the fabric device. Furthermore, the device requires only $3 \mu \mathrm{L}$ of fluid sample to complete the measurement compared to spectroscopic method $( \pm 50 \mu \mathrm{L})$, hence providing a higher temporal resolution and reduced sampling time. The system could potentially provide a real time assessment of the degradation behavior, a new studied aspect in biodegradable metals research.
\end{abstract}

Keywords: biodegradable metal, biosensor, fabric device, magnesium, microdialysis

\section{INTRODUCTION}

The human body is considered as an aggressive environment for implanted metal alloys due to its highly oxyge- nated saline electrolyte [1]. Hence, for decades, it has been agreed that an ideal material for a metal implant must be corrosion-resistant. However, the paradigm has been shifted by the introduction of biodegradable metals as the model material for implants assisting the treatment of temporary clinical problems [2]. Magnesium, iron, zinc and their alloys are the three types of metals that have been studied as biodegradable metals that degrade in physiological environment via corrosion. In this article, the term of corrosion is therefore interchangeable with degradation. Magnesium possesses interesting mechanical properties, where its Young's modulus and compressive strength are close to those of cortical bone [3,4]. Magnesium-based biodegradable metals have received attention on almost every aspects of research including material development, in vitro degradation, in vivo animal studies, pre-clinical trials and commercialization since their first introduction in 2003 [5-9]. However, one aspect was least considered, the measurement of its degradation kinetics continuously using a rapid detection technique. This measurement will further enable the study of in vivo degradation of magnesium or other biodegradable metal implants, thus allowing a better design of implants.

The most used techniques to assess the in vivo degradation of biodegradable metals include implant retrieval analysis assisted by scanning electron microscopy (SEM), X-ray diffraction (XRD) and energy dispersive Xray spectroscopy (EDS) [10]; non-invasive microtomography (micro-CT) [11,12]; X-ray radiography [13] and the least accessible synchrotron micro-CT $[14,15]$.

\footnotetext{
${ }^{1}$ Faculty of Biosciences and Medical Engineering, Universiti Teknologi Malaysia, 81310 Johor Bahru, Malaysia

${ }^{2}$ Faculty of Science and Technology, Universiti Kebangsaan Malaysia, 43600 Bangi, Selangor Darul Ehsan, Malaysia

${ }^{3}$ Department of Biomedical Engineering, Faculty of Life Sciences and Technology, Swiss German University, Tangerang 15143, Indonesia

${ }^{4}$ Instituto de Microelectrónica de Barcelona (IMB-CNM), CSIC, Campus UAB, 08193 Bellaterra, Spain

${ }^{5}$ Department of Mining, Metallurgical and Materials Engineering \& CHU de Québec Research Center, Quebec City, G1V 0A6, Canada

† These two authors contributed equally to this work.

* Corresponding author (email: hendra.hermawan@gmn.ulaval.ca)
} 
These techniques are capable of revealing the degradation mechanism of the implant, including the determination of degradation products and its composition; however no real time data can be obtained especially on the degradation kinetics. Studies that assessed the continuous degradation measurements are much more recent. Schumacher et al. [16] used microdialysis to investigate the reaction interface between pure magnesium and tissue in isolated perfused bovine udder model and examined its biocompatibility using prostaglandin E2 (PGE2) and tumor necrosis factor alpha (TNF- $\alpha$ ) concentrations, which served as indicators of inflammation. Although their work has managed to penetrate the ex vivo behavior of the implant, the results were not measured in real time because they still relied on the offline spectrophotometric measurements. Another work by Ulrich et al. [17] utilized a micro-flow-capillary $(\mu \mathrm{FC})$ that was online-coupled via a flow injection analyzing system (FIAS) to an inductively coupled plasma mass spectrometer (ICP-MS) setup with electrochemical control to investigate the degradation behavior of magnesium alloys. However, the generated hydrogen $\left(\mathrm{H}_{2}\right)$ gas bubbles were suspected to prevent sufficient mixing in the circulating solution within the capillary, hence lack of accuracy was reported in the results. A latest work by Zhao et al. [18] measured the realtime concentration of magnesium ions, hydroxyl ions and hydrogen gas using sensory system composed of in-house capillary $\mathrm{pH}$ and $\mathrm{Mg}^{2+}$ microsensors and a hydrogen gas sensor. The sensor was able to map the hydrogen concentration in the vicinity of an implanted magnesium alloy. The group continued their work by developing a transdermally electrochemical hydrogen microsensor and tested it for measuring the biodegradation of various magnesium implants in mouse. The sensor was able to easily detect hydrogen at the concentration as low as 30 $400 \mu \mathrm{mol} \mathrm{L}^{-1}$ permeating through the skin with a fast response time of $30 \mathrm{~s}$. However, due to the dependence to the skin permeability that the hydrogen can permeate through, this technique might not be applicable to deep implants such as on the thigh bone $[19,20]$.

Chemical sensors such as ion selective electrodes (ISE) are capable of detecting fluid variables such as $\mathrm{pH}$ and concentration of various ions $\left(\mathrm{Mg}^{2+}, \mathrm{K}^{+}, \mathrm{Ca}^{2+}\right.$, etc.). Magnesium ion selective electrodes (Mg-ISE) have been essentially used to determine intracellular free $\mathrm{Mg}^{2+}$ ions concentration [21]. However, the development process is often complicated and it exhibits limited selectivity since $\mathrm{Ca}^{2+}$ ions are a common interfering species [22]. Biosensors using enzymes as the bio-recognition molecule are recognized for their high selectivity and specificity, whilst electrochemical biosensors are the most popular choices for their sensitivity [23]. Nevertheless, both ISE and electrochemical biosensors consist of electrodes that are constituted by metal, typically platinum, hence presenting biocompatibility issues. When the sensor is implanted in tissue, it is recognized as a foreign body by the immune system, which triggers a cascade immune response. Proteins and blood vessels form a capsule around the sensor (biofouling), consequently compromising its sensing capabilities [24]. In order to overcome this issue, microdialysis has been used over the last 30 years and coupled to a range of detection techniques such as biosensors. Microdialysis, a sampling technique first developed to mimic a blood capillary, was used to sample neurochemicals from a rodent's brain [25]. Over the years, microdialysis has been used for other tissues such as gastrointestinal [26] and cardiovascular [27] as well as implanted subcutaneously or intravenously [27,28]. Microdialysis use has been reported for up to five days in patients allowing to sample ions and small molecules without extracting blood cells or other large components due to the small molecular weight cut-off of membrane [29]. Microdialysis combined with biosensors presents a synergetic effect allowing a realtime monitoring of degradation process. Microdialysis overcomes the biocompatibility issues of biosensors, while biosensors increase the temporal resolution of the sampling technique. A microdialysis probe can be inserted beneath the skin thus allowing a degradation measurement of a deep implant. Therefore, in this study we aim to use microdialysis coupled with magnesium biosensor to monitor the concentration of $\mathrm{Mg}^{2+}$ ions released from the degradation of magnesium specimen in Ringer's solution. Success in developing this system in vitro will allow a further exploration for future in vivo setting.

\section{EXPERIMENTAL SECTION}

\section{Specimen preparation and fabrication of $\mathrm{Mg}^{2+}$ biosensor}

Specimens (diameter $=3.2 \mathrm{~mm}$, length $=10 \mathrm{~mm}$ ) were prepared from pure magnesium rods $(99.9 \%$ purity, Goodfellow, UK). They were polished using abrasive paper

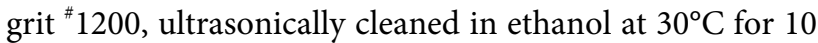
min, etched with $2 \%$ nital solution to remove oxides, and finally rinsed with distilled water before drying in the desiccator for an hour. A fabric-based electrochemical device (FED) was used as described previously $[30,31]$ for the development of the $\mathrm{Mg}^{2+}$ biosensor. Cotton fabric provides an optimum and flexible platform for manual fabrication of electrodes. Furthermore, the hierarchical structure of the natural cellulose fibers allows a robust 
entrapment of enzymes within the fibers without requiring additional artificial membranes or chemicals for their immobilization [32]. Briefly, the fabrication of FED consists of a white plain cotton fabric (Jadi Batek Gallery, Malaysia) that was previously scoured using anhydrous sodium carbonate [30]. Conductive paste (Gwent Electronics Material, UK) was used to embed the electrodes onto the cotton fabric. Carbon graphite paste modified with Prussian blue (C-PB) was used as the working and counter electrodes, while silver/silver chloride (Ag/AgCl) paste was used as the reference electrode. This procedure was followed by wax-patterning of the device in order to create a hydrophobic barrier for the area surrounding the sample placement/reaction zone. Then, two different enzymes were entrapped within the cellulose fibers of the FED. An amount of $20 \mathrm{mg} \mathrm{mL}^{-1}$ of each glycerol kinase (GK, 25-75 kU, Cellulomonas sp.) and glycerol-3-phosphate oxidase (GPOx, $70 \mathrm{kU}$, Aerococcus viridians sp.) enzymes (Sigma Aldrich, Malaysia) were dissolved in $0.1 \mathrm{~mol} \mathrm{~L}^{-1}$ phosphate buffer solution (PBS). An amount of $3 \mu \mathrm{L}$ of the enzyme mixture (4:1, GK:GPOx) was then drop-coated onto the reaction zone of the FED and left to dry at room temperature $\left(\sim 25^{\circ} \mathrm{C}\right)$ for an hour. The $\mathrm{Mg}^{2+}$ biosensor functions based on the reaction of kinase enzyme which requires adenosine triphosphate (ATP) for the phosphorylation of the substrate and magnesium as a cofactor for the reaction to occur $[33,34]$. The inset in Fig. 1 shows the mechanism of the reaction. Glycerol is phosphorylated by GK and the product of this reaction is then oxidized by GPO $x$ which in turn produces hydrogen peroxide $\left(\mathrm{H}_{2} \mathrm{O}_{2}\right)$. The $\mathrm{H}_{2} \mathrm{O}_{2}$ then reacts with Prussian blue at the working electrode of the FED resulting in electrochemical signal that is proportional to the concentration of $\mathrm{Mg}^{2+}$, provided that everything else remains constant.

\section{Immersion test and microdialysis sampling}

The magnesium specimens were initial weighed $\left(W_{\mathrm{i}}\right)$, then immersed inside beakers (one specimen/beaker) containing a buffered Ringer's solution that consisted of 118.4 mmol L ${ }^{-1}$ sodium chloride $(\mathrm{NaCl}), 4.7 \mathrm{mmol} \mathrm{L}^{-1}$ potassium chloride $(\mathrm{KCl}), 2.52 \mathrm{mmol} \mathrm{L}^{-1}$ calcium chloride $\left(\mathrm{CaCl}_{2}\right)$, $1.18 \mathrm{mmol} \mathrm{L}^{-1}$ monopotassium phosphate $\left(\mathrm{KH}_{2} \mathrm{PO}_{4}\right)$ and $25.01 \mathrm{mmol} \mathrm{L}^{-1}$ sodium bicarbonate $\left(\mathrm{NaHCO}_{3}\right)$ in $1 \mathrm{~L}$ of distilled water. All chemicals were of analytical reagents grade (Sigma Aldrich, Malaysia) unless stated otherwise. Three specimens were allowed to degrade in this solution for 1, 2 and 5 days, respectively. $\mathrm{pH}$ of the Ringer's solution was measured every $24 \mathrm{~h}$ for the period of 5 days. After the immersion test was completed, the corrosion product was removed from the specimens by immersing in chromate acid solution ( $200 \mathrm{~g} \mathrm{~L}^{-1} \mathrm{CrO}_{3}+10 \mathrm{~g} \mathrm{~L}^{-1} \mathrm{AgNO}_{3}$ ) at ambient temperature for 5-10 $\mathrm{min}$ and rinsed thoroughly with distilled water before drying in the desiccator for $24 \mathrm{~h}$ [35]. This cleaning process was repeated until the final weight $\left(W_{\mathrm{f}}\right)$ of the specimens measured after $24 \mathrm{~h}$ became constant. The weight loss ( $\mathrm{mg}$ ) of the specimens $\left(W_{\mathrm{i}}-W_{\mathrm{f}}\right)$ was then plotted against immersion time (hour). The result was used for making correlation between the degradation rate by weight loss and by $\mathrm{Mg}^{2+}$ concentration measured by the biosensor. The microdialysis probe (MAB 9.20.3 series, Microbiotech, Sweden) was immersed alongside the specimens during the immersion tests. The microdialysis inlet was connected to a 1-mL syringe mounted on a NE-300 infusion syringe pump (New Era, Malaysia) and perfused with the Ringer's solution at a flow rate of $1.5 \mu \mathrm{L} \mathrm{min}{ }^{-1}$ for $90 \mathrm{~min}$. At the outlet, the dialysate was collected in vials. Fig. 1 shows the experimental setup. Since the microdialysis probe recovered a percentage of the concentration of the bulk, the microdialysis recovery coefficient was determined by collecting a sample of the immersion solution using pipettes. Relative recovery $(R)$ is a critical parameter that provides a percentage of the ratio between the concentration in the dialysate $\left(C_{\text {dial }}\right)$ and the concentration in the bulk $\left(C_{\text {bulk }}\right)$ [36], as per Equation (1):

$$
R=\frac{C_{\text {dial }}}{C_{\text {bulk }}} \times 100 \% \text {. }
$$

\section{Electrochemical measurement of the device}

A STAT400 portable potentiostat (Dropsens, Spain) was used for the electrochemical measurements. The electrodes were connected to the potentiostat using connector clips (Fig. 1). The electrochemical signals were measured and displayed using the manufacturer DropView software. Prior to the enzymes immobilization, characterization of the electrochemical behavior of C-PB was performed using cyclic voltammetry $(\mathrm{CV})$ technique. For this purpose, $3 \mu \mathrm{L}$ of $0.1 \mathrm{~mol} \mathrm{~L}^{-1} \mathrm{PBS}$ was placed at the sample placement region of the FED and $\mathrm{CV}$ was performed at different scan rates $\left(10,25\right.$ and $\left.50 \mathrm{mV} \mathrm{s}^{-1}\right)$. Next, the optimum detection potential of $\mathrm{Mg}^{2+} \mathrm{FED}$ was investigated for the reliable detection of $\mathrm{H}_{2} \mathrm{O}_{2}$ (the product of the enzyme-catalyzed reaction) at the C-PB/GK/GPO $x$ electrodes [31]. Since the substrate of the enzyme-catalyzed reaction was glycerol and not $\mathrm{Mg}^{2+}$ ion, the amount of glycerol required for the biosensor was investigated. Glycerol standards (0.05, 0.1, $0.2,0.5,1$ and $3 \mathrm{mmol} \mathrm{L}^{-1}$ ) were prepared in a mixture of 3 mmol L ${ }^{-1}$ magnesium chloride $\left(\mathrm{MgCl}_{2}\right), 3 \mathrm{mmol} \mathrm{L}{ }^{-1}$ ATP and $0.1 \mathrm{~mol} \mathrm{~L}^{-1} \mathrm{PBS}$ which were similar to those of the work of Ghica et al. [34]. An amount of $3 \mu \mathrm{L}$ of each 


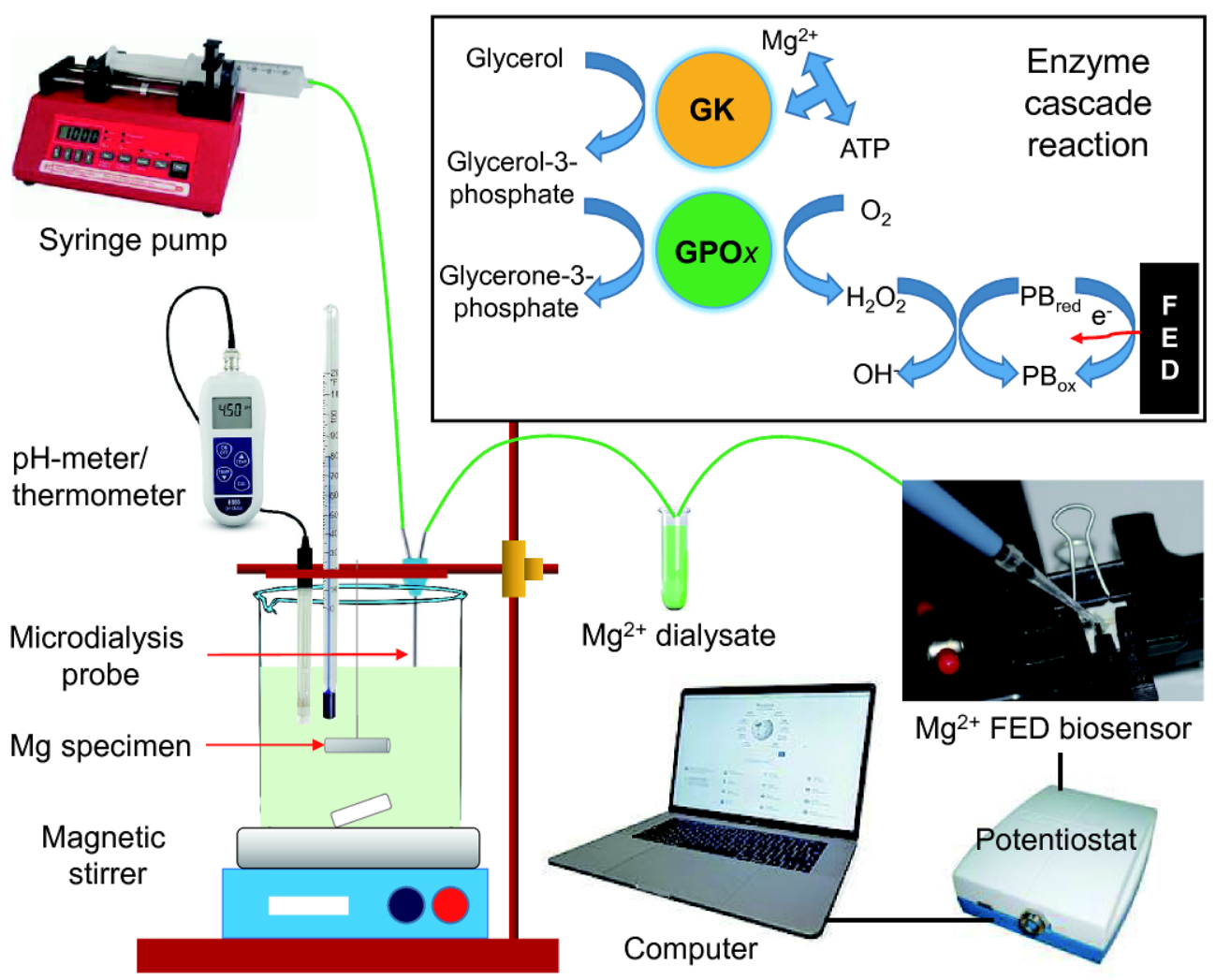

Figure 1 Schematic diagram of the experimental setup consisting of the microdialysis probe (sampling tool), FED (biosensor) and potentiostat/ computer (converter chemical to electrical analysis). Dialysate is dropped at the sample placement (reaction zone) of the FED that was immobilized with the GK and GPOx enzymes to detect $\mathrm{Mg}^{2+}$ ions via enzymes cascade reaction (inset).

glycerol standard was dropped at the sample placement region of the FED and $\mathrm{CV}$ was performed at working potential range from -0.5 to $+0.5 \mathrm{~V}$ at a potential scan rate of $10 \mathrm{mV} \mathrm{s}^{-1}$. CV was used for the calibration of $\mathrm{Mg}^{2+}$-FED biosensor with the $\mathrm{Mg}^{2+}$ standards prepared using solution

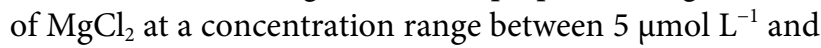
$1 \mathrm{mmol} \mathrm{L}{ }^{-1}$ in $500 \mu \mathrm{mol} \mathrm{L}^{-1}$ glycerol, $3 \mathrm{mmol} \mathrm{L}^{-1} \mathrm{ATP}$ and $0.1 \mathrm{~mol} \mathrm{~L}^{-1} \mathrm{PBS}$ at a potential scan rate of $10 \mathrm{mV} \mathrm{s}^{-1}$. All the standards and buffer solutions were kept at $4^{\circ} \mathrm{C}$ when not in use. Fresh solutions were prepared weekly to retain freshness. For interference testing, common metabolites and biomolecules present in physiological fluids such as $0.2 \mathrm{mmol} \mathrm{L}^{-1}$ of D-(+)-glucose ( $\left.\geq 99.5 \%\right)$, L-ascorbic acid (vitamin $\mathrm{C}$ ) and urea ( $\geq 99.5 \%$ ) were added into $0.2 \mathrm{mmol}$ $\mathrm{L}^{-1} \mathrm{MgCl}_{2}$ standards (1:1 ratio of interferences to $\mathrm{MgCl}_{2}$ ). The CV scans were then conducted at a potential scan rate of $10 \mathrm{mV} \mathrm{s}^{-1}$ within a working potential range from -0.5 to $+0.5 \mathrm{~V}$ for all the interference solutions.

\section{RESULTS AND DISCUSSION}

Fig. $2 \mathrm{a}$ shows the variation of weight loss and $\mathrm{pH}$ of the
Ringer's solution over the immersion time. Overall, the weight loss increases with the longer immersion time at $1.79 \mathrm{mg} \mathrm{cm}^{-2} \mathrm{day}^{-1}$. Similar increase is observed for the $\mathrm{pH}$ of the Ringer's solution over the immersion time. The oxidation of magnesium metal to $\mathrm{Mg}^{2+}$ ions on the anode is balanced by the reduction of water to form hydrogen gas and $\mathrm{OH}^{-}$on the cathode. The weight loss over immersion time can be related to the general corrosion, a phenomenon previously reported by Wang et al. [37]. The higher increment of weight loss and $\mathrm{pH}$ on the period of day 1 to day 2 compared to the period of day 2 to day 5 could be related to the formation of adherent corrosion products (e.g., magnesium hydroxide and phosphates) on the specimen's surface that slows down corrosion process temporarily [38]. However, other factors besides the chemical reaction that contribute to the weight loss of magnesium during degradation were not considered in this study, such as the deposition of degradation products $\left(\mathrm{MgCO}_{3}\right.$, $\mathrm{CaCO}_{3}, \mathrm{NaCl}$ ) which increases the final weight, and the dissociation of broken piece of magnesium which reduces the final weight [39]. 

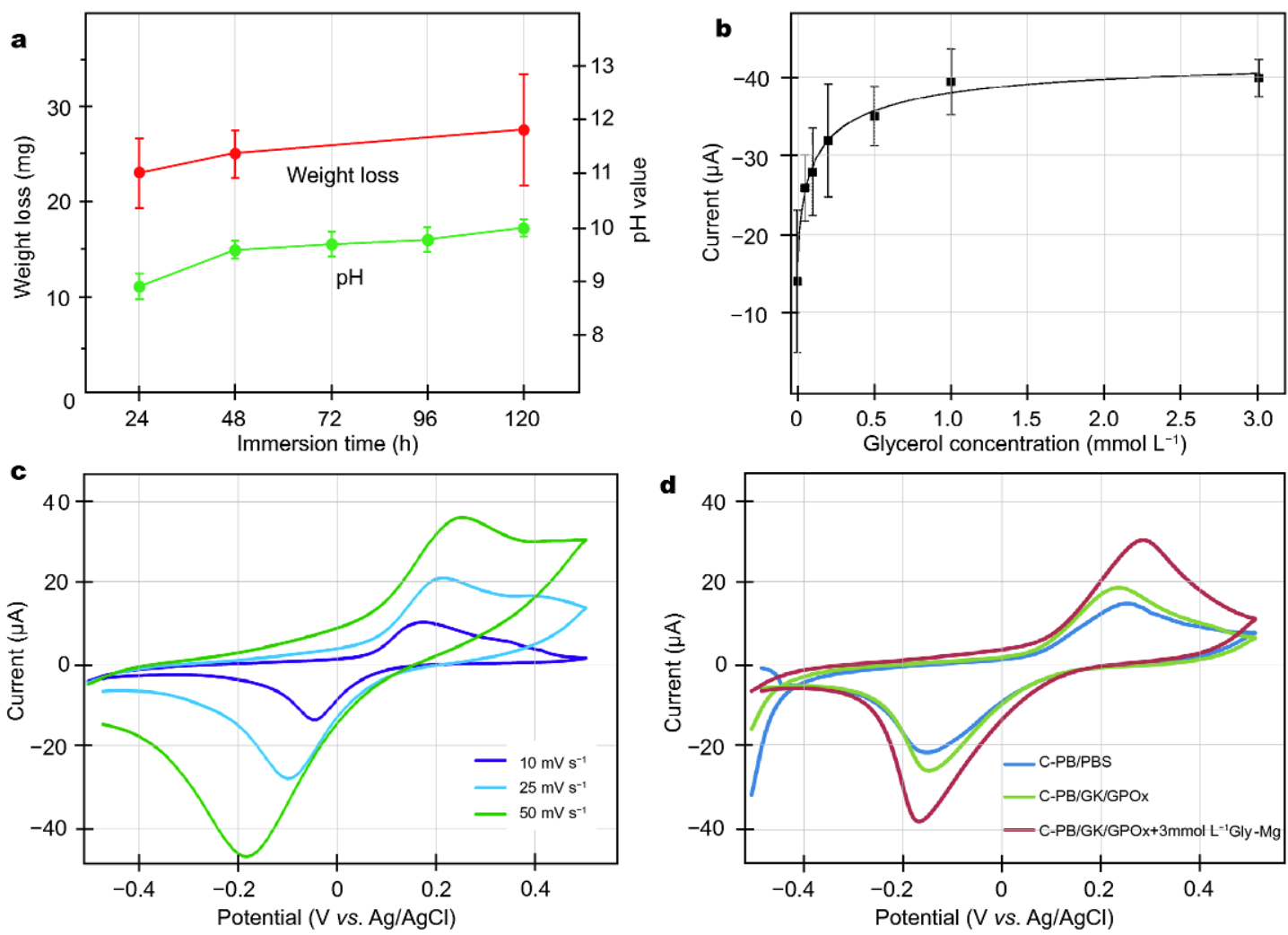

Figure 2 (a) Weight loss of magnesium specimens and $\mathrm{pH}$ of Ringer's solution from day 1 to day 5. (b) Calibration of Mg ${ }^{2+}$-FED for glycerol samples $\left(0.5 \mathrm{mmol} \mathrm{L} \mathrm{L}^{-1}\right.$ of glycerol provides the highest response before the saturation of the enzyme). (c) CV scan rate dependence on FED before immobilization was performed (measurements were taken at 10,25 and $50 \mathrm{mV} \mathrm{s}^{-1}$ scan rates). (d) CV curves of the C-PB electrodes at a range between

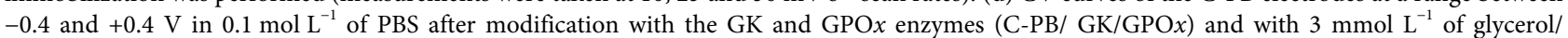
magnesium.

The enzyme-catalyzed reaction occurring on the C-PB/ GK/GPO $x$ electrodes is first due to the phosphorylation of glycerol. As mentioned in the method, $\mathrm{Mg}^{2+}$ ions are required as they act as the cofactor for the reaction catalyzed by the kinase enzyme. When glycerol is kept constant, the current produced by the increase of the cofactor can be detected. Hence, the amount of glycerol required for the biosensor was investigated using different concentrations (0.05-3 mmol L ${ }^{-1}$ ) of glycerol standards in PBS solution with constant amounts of $\mathrm{MgCl}_{2}$ and ATP. The CVs of the $\mathrm{C}-\mathrm{PB} / \mathrm{GK} / \mathrm{GPO} x$ were performed using these glycerol standard solutions. The calibration curve for glycerol was obtained from the cathodic current of the $\mathrm{CV}$ at potential of $-0.2 \mathrm{~V} v s . \mathrm{Ag} / \mathrm{AgCl}$. Fig. $2 \mathrm{~b}$ shows the calibration curve of the sensor with glycerol standard solutions. The curve plateaus following the addition of $1 \mathrm{mmol} \mathrm{L}^{-1}$ of glycerol indicate the saturation of the GK enzyme. The optimal response was chosen as that before saturation occured, since it allowed the response to increase with an increase of $\mathrm{Mg}^{2+}$ ions concentration. Hence, the concentration of
$0.5 \mathrm{mmol} \mathrm{L}-1$ of glycerol was selected to prepare the $\mathrm{Mg}^{2+}$ samples.

The $3 \mu \mathrm{L}$ of $0.1 \mathrm{~mol} \mathrm{~L}^{-1} \mathrm{PBS}$ were placed on the reaction zone and the CVs within the potential limits of -0.5 and $+0.5 \mathrm{~V}$ at different potential scan rates $\left(10,25,50 \mathrm{mV} \mathrm{s}^{-1}\right)$ were performed to characterize the electrochemical performance of the C-PB electrodes on the FED. Fig. 2c shows the $\mathrm{CV}$ characteristic indicating a diffusion controlled electron-transfer process similar to conventional electrochemical cells [31]. The anodic and cathodic peaks correspond to the following redox reaction (Equation (2)):

$$
\mathrm{Fe}_{4}^{\mathrm{III}}\left[\mathrm{Fe}^{\mathrm{II}}(\mathrm{CN})_{6}\right]_{3}+4 \mathrm{~K}^{+}+4 \mathrm{e}^{-} \leftrightarrow \mathrm{K}_{4} \mathrm{Fe}_{4}^{\mathrm{II}}\left[\mathrm{Fe}^{\mathrm{II}}(\mathrm{CN})_{6}\right]_{3} .
$$

In order to optimize the detection potential of the $\mathrm{Mg}^{2+}$ FED biosensor for $\mathrm{H}_{2} \mathrm{O}_{2}$ detection, the C-PB/GK/GPOx electrodes were characterized using $\mathrm{CV}$ at a range between -0.4 and $+0.4 \mathrm{~V}$ in $0.1 \mathrm{~mol} \mathrm{~L}^{-1}$ of PBS (lack of $\mathrm{H}_{2} \mathrm{O}_{2}$ ). Results showed the characteristic redox peaks of $\mathrm{PB}$, however, the peak current of C-PB/GK/GPO $x$ was larger than the C-PB only, due to the increase in efficiency of the 

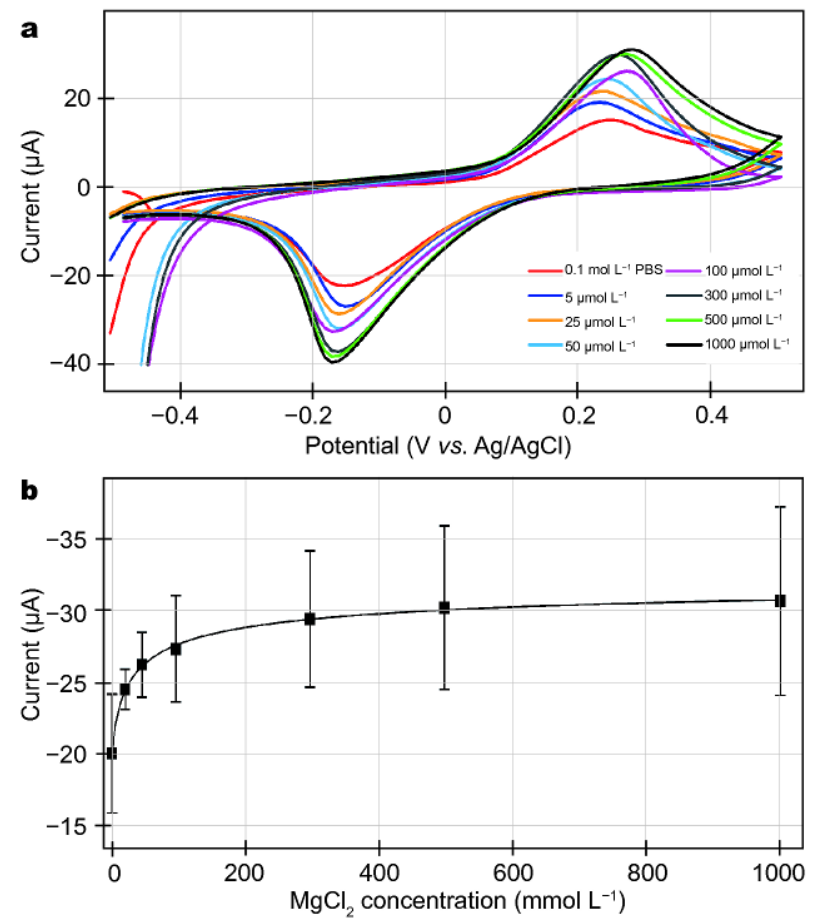

Figure 3 Calibration of $\mathrm{Mg}^{2+}$-FED for $\mathrm{Mg}^{2+}$ samples: (a) $\mathrm{CV}$ of different concentrations of $\mathrm{MgCl}_{2}$ to determine the sensitivity of FED biosensor, (b) non-linear regression of $\mathrm{MgCl}_{2}$ fitted by the Hill's equation.

C-PB electrodes after modification with the GK and GPO $x$ enzymes (Fig. 2d). An even larger peak current was observed when $3 \mathrm{mmol} \mathrm{L}{ }^{-1}$ of glycerol/magnesium was used compared with PBS only. The applied potential in the CV region between -0.2 and $+0.2 \mathrm{~V}\left(\mathrm{H}_{2} \mathrm{O}_{2}\right.$ in $\mathrm{C}$-PB electrodes region) was further investigated and the signal-to-background (S/B) ratios of each potential showed the highest S/ $\mathrm{B}$ ratio at $-0.2 \mathrm{~V}$ (data not shown). This low detection potential reduces the signal from common electrochemical interfering substance present in real samples.

Since the activity of enzymatic reaction is enhanced in the presence of $\mathrm{Mg}^{2+}$ ions, an increment in the concentration of $\mathrm{Mg}^{2+}$ provides a proportional increase in signal. After determining the optimal concentration of glycerol, the CVs of C-PB/GK/GPO $x$ were obtained at different concentrations of $\mathrm{Mg}^{2+}$ standards solution (0-1 $\left.\mathrm{mmol} \mathrm{L}^{-1}\right)$ as shown in Fig. 3a. The calibration curve (Fig. 3b) was obtained from the cathodic currents of the $\mathrm{CV}$ at a potential of $-0.2 \mathrm{~V}$ vs. $\mathrm{Ag} / \mathrm{AgCl}$. The curve was fitted using a non-linear regression using the Hill's equation (Equation (3)), which generates a sigmoid fit:

$$
\mathrm{I}=\frac{I_{\max }}{1+\left[\frac{K_{\mathrm{M}}}{\left[S_{]}\right.}\right]^{n}},
$$

where, $I$ is the current signal obtained, $I_{\max }$ is the maximum current signal, $n$ is the Hill coefficient, $[S]$ is the concentration of substrate and $K_{\mathrm{M}}$ is the Michaelis-Menten constant, which is the $[S]$ value at $I_{\max } / 2$.

The Hill's equation coefficients of the $\mathrm{Mg}^{2+}$ biosensor were then calculated. $I_{\max }$, the current at the signal plateau, was $-32.81 \pm 0.38 \mu \mathrm{A}$. The plateau response is a sign of the saturation of the enzymes, the biorecognition molecules of the biosensor. Hence, high concentration samples required to be diluted prior to the determination. The $K_{\mathrm{M}}$ of the enzymatic mix used in this biosensor was $7.90 \pm 0.12$ mmol L $\mathrm{L}^{-1}$, which is the substrate concentration corresponding to half of the maximum signal and $n$ was the Hill coefficient, $0.48 \pm 4.25$, which denotes a cooperative binding. The calibration plot shows a pseudo-linear response from $0.005 \mathrm{mmol} \mathrm{L}^{-1}$ until approximately $0.1 \mathrm{mmol} \mathrm{L}^{-1}\left(R^{2}\right.$ $=0.756)$. From the slope of the linear calibration the sensitivity of the sensor was calculated (0.0679 $\left.\mu \mathrm{A}\left(\mathrm{mmol} \mathrm{L}^{-1}\right)^{-1}\right)$. The limit of detection $(\mathrm{LOD}=10.162$ $\mu \mathrm{mol} \mathrm{L} \mathrm{L}^{-1}$ and limit of quantification (LOQ $=33.872$ ) of the device were calculated from standard deviation $(s)$ of the blank as the concentrations that produced the signal at 3 and $10 \mathrm{~s}$, respectively for three separate devices. The repeatability of the device was calculated using the same $\mathrm{Mg}^{2+}$-FED three times for each $\mathrm{Mg}^{2+}$ concentration and the obtained relative standard deviation (\%RSD) was $5.71 \%$ for $25 \mu \mathrm{mol} \mathrm{L}{ }^{-1}$ of $\mathrm{Mg}^{2+}$, while the reproducibility was measured using three different devices for 50 and 1000 $\mu \mathrm{mol} \mathrm{L}{ }^{-1}$ of $\mathrm{Mg}^{2+}$, concentrations and the attained \%RSD was $8.64 \%$ and $21.4 \%$, respectively.

Unlike the $\mathrm{Mg}^{2+}$ ion selective electrode, other bivalent metals such as $\mathrm{Ca}^{2+}$ or heavy metals does not affect the FED response due to the specificity of the enzyme to the substrate, in this case glycerol. Kinase enzyme uses $\mathrm{Mg}^{2+}$ ions as a cofactor, but other bivalent heavy metals do not affect the kinetics of the reaction. On the other hand, although enzymes are specific biorecognition molecules, other organic and electroactive substrates could sometimes produce an electrochemical response. This could perturb the signal and cause misleading results. Therefore, interferences testing were conducted to test the reliability of the sensor towards foreign compounds. Ascorbic acids, glucose and urea are among the compounds that could interfere with the chemical signal of the biosensor. The relative response with ascorbic acid was $1.26 \%$, then $1.18 \%$ with glucose and $1.13 \%$ with urea. Since the FED biosensor showed a rate of interference of $\sim 1 \%$ when exposed to a $200 \mu \mathrm{mol} \mathrm{L}{ }^{-1}$ of other chemicals, it was demonstrated that the sensor presented a $\sim 99 \%$ of selectivity.

Bulk and dialysate were tested on the FED to obtain 

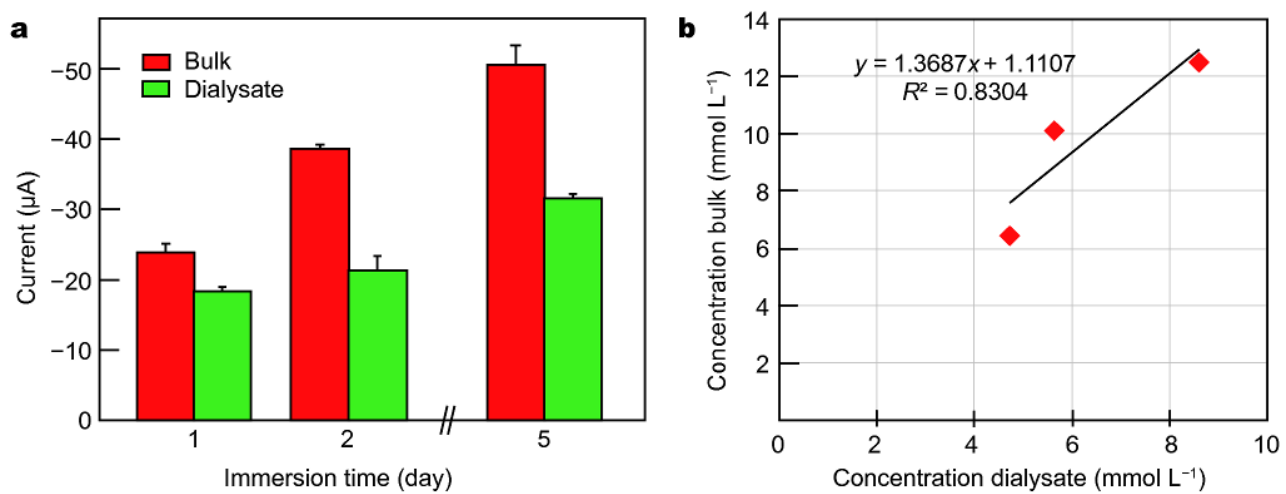

Figure 4 Measurement of current signal for bulk and dialysate samples up to 5 days immersion time (a), and their linear correlation (b).

current signals for each respective sample of different immersion days. Fig. 4a shows the bar graph of current signals for replications of bulk samples using three different FED sensors. The average current $(n=3)$ for bulk samples on day 5 is $-50.33 \pm 2.46 \mu \mathrm{A}$, whereas on day 1 is $-23.73 \pm 0.93 \mu \mathrm{A}$. The increment of current signals is about two times higher within four days. This occurs due to the longer immersion of the magnesium sample in Ringer's solution, resulting in more $\mathrm{Mg}^{2+}$ ions released. Subsequently, when a highly concentrated $\mathrm{Mg}^{2+}$ ions bulk solution was placed on the working region of FED, the catalyzed enzyme-substrate will produce more $\mathrm{H}_{2} \mathrm{O}_{2}$. This compound (i.e., $\mathrm{H}_{2} \mathrm{O}_{2}$ ) is translated into electrical current signal proportional to the concentration of $\mathrm{Mg}^{2+}$ ions. The same phenomenon occurs for dialysate samples. However, the current produced for dialysate sample on day 5 , which was supposed to be the highest current, was only -31.18 $\pm 0.66 \mu \mathrm{A}$ (as seen in Fig. 4a). Increment has been linear for pure magnesium specimen without any sign of plateau after 5 days; hence we presumed longer times are required in order to observe the overall kinetics of the corrosion.

Clearly as shown in Fig. 4a, the current value of dialysate is lower compared to that of bulk samples. The linear regression correlation factor is 0.8304 ; while the chi-square test's $p$-value is 0.1504 , indicating a poor correlation between the two lines (Fig. 4b). However, this test was only done to find out the recovery of the probe and then be able to extrapolate them to an actual value of magnesium in the bulk. Based on calibration, the $\mathrm{Mg}^{2+}$ concentrations in bulk/dialysate samples for day 1, day 2 and day 5 are: 6.52/ $4.73,10.17 / 5.61$ and $12.56 / 8.60 \mathrm{mmol} \mathrm{L}^{-1}$, respectively. This suggests that there are losses in the microdialysis membrane and that the total equilibrium cannot be established with constant perfusion into microdialysis probe. From these results, the recovery of samples (Equation (1)) was $72.56 \%$ in day $1,55.17 \%$ in day 2 and $68.42 \%$ in day 5 . The range of concentration losses was between $55 \%$ and $73 \%$, where it could be concluded that the recovery is very high. The rate at which these analytes were exchanged across the semipermeable active membrane is expressed as the analyte extraction efficiency. This calibration factor (recovery) shows that the efficiency of concentration gained in this study was due to the low perfusion flow rate (i.e., $1.5 \mu \mathrm{L} \mathrm{min}{ }^{-1}$ ) that was applied.

Finally, we analyze the correlation between degradation rate calculated from the weight loss and from the $\mathrm{Mg}^{2+}$ concentration measured by the biosensor. The overall degradation rate calculated from the weight loss at 5 days immersion time is $1.79 \mathrm{mg} \mathrm{cm}^{-2} \mathrm{day}^{-1}$. Using a simple stoichiometry correlation of $\mathrm{Mg}+2 \mathrm{H}_{2} \mathrm{O} \rightarrow \mathrm{Mg}^{2+}+2 \mathrm{OH}^{-}+$ $\mathrm{H}_{2}$, the corrosion rate calculated from the measured concentration of $\mathrm{Mg}^{2+}$ in bulk on day $5\left(12.56 \mathrm{mmol} \mathrm{L}^{-1}\right)$ is $1.56 \mathrm{mg} \mathrm{cm}{ }^{-2}$ day $^{-1}$. This tells a good measurement has been obtained by the biosensor for the period of immersion test conducted in this work. Further improvement to the accuracy of the system can be done by carefully analyzing other factors than chemical reaction that contribute to the weight loss of magnesium during degradation (deposition of degradation products and dissociation of broken piece of magnesium), verifying each calculated $\mathrm{Mg}^{2+}$ concentration using ICP-MS as well as setting-up an optimum perfusion rate.

\section{CONCLUSIONS}

A magnesium implant degradation monitoring system consisting of microdialysis sampling and electrochemical detection with a fabric-based enzymatic biosensor has been successfully developed and validated. The system measures $\mathrm{Mg}^{2+}$ samples at a small sample volume and more frequent period, and thus reduces sampling time 
while increasing the temporal resolution. The correlation was observed between the $\mathrm{Mg}^{2+}$ concentration in both the dialysate and the bulk. The sensitivity of the biosensor is $67.48 \mu \mathrm{A} \mathrm{mmol}^{-1} \mathrm{~L}$ with $\sim 1 \%$ chance of interference and thus allows a lower level $\mathrm{Mg}^{2+}$ detection. Although further studies are required in order to optimize the combination between the biosensor and the microdialysis outlet, the system has shown the capability to detect rapidly the dialysate $\mathrm{Mg}^{2+}$ levels electrochemically and could be suitable for monitoring the in vivo degradation of $\mathrm{Mg}$ implants in real time.

Received 19 May 2017; accepted 27 June 2017; published online 8 August 2017

1 Hansen DC. Metal corrosion in the human body: the ultimate biocorrosion scenario. Electrochem Soc Interface, 2008, 17: 31-34

2 Nasution AK, Hermawan H. Degradable biomaterials for temporary medical implants. Adv Struct Mater, 2016, 58: 127-160

3 Krause A, von der Höh N, Bormann D, et al. Degradation behaviour and mechanical properties of magnesium implants in rabbit tibiae. J Mater Sci, 2010, 45: 624-632

4 Li KK, Wang B, Chai J, et al. Electrochemical behaviour and cytocompatibility of nano-fluoridated apatite coating on biodegradable magnesium alloy by simple chemical conversion. Sci China Technol Sci, 2013, 56: 80-83

5 Heublein B. Biocorrosion of magnesium alloys: a new principle in cardiovascular implant technology? Heart, 2003, 89: 651-656

6 Staiger MP, Pietak AM, Huadmai J, et al. Magnesium and its alloys as orthopedic biomaterials: a review. Biomaterials, 2006, 27: 17281734

7 Witte F, Hort N, Vogt C, et al. Degradable biomaterials based on magnesium corrosion. Curr Opin Solid State Mater Sci, 2008, 12: 63-72

8 Kirkland NT. Magnesium biomaterials: past, present and future. Corrosion Eng Sci Tech, 2012, 47: 322-328

9 Lee JW, Han HS, Han KJ, et al. Long-term clinical study and multiscale analysis of in vivo biodegradation mechanism of $\mathrm{Mg}$ alloy. Proc Natl Acad Sci USA, 2016, 113: 716-721

10 Witte $\mathrm{F}, \mathrm{Kaese} \mathrm{V}$, Haferkamp $\mathrm{H}$, et al. In vivo corrosion of four magnesium alloys and the associated bone response. Biomaterials, 2005, 26: 3557-3563

11 Yang JX, Cui FZ, Lee IS, et al. In vivo biocompatibility and degradation behavior of $\mathrm{Mg}$ alloy coated by calcium phosphate in a rabbit model. J BioMater Appl, 2012, 27: 153-164

12 Huehnerschulte TA, Reifenrath J, von Rechenberg B, et al. In vivo assessment of the host reactions to the biodegradation of the two novel magnesium alloys ZEK100 and AX30 in an animal model. BioMed Eng Online, 2012, 11: 14

13 Ulum MF, Nasution AK, Yusop AH, et al. Evidences of in vivo bioactivity of Fe-bioceramic composites for temporary bone implants. J Biomed Mater Res, 2015, 103: 1354-1365

14 Witte F, Fischer J, Nellesen J, et al. In vitro and in vivo corrosion measurements of magnesium alloys. Biomaterials, 2006, 27: 10131018

15 Witte F, Fischer J, Nellesen J, et al. In vivo corrosion and corrosion protection of magnesium alloy LAE442. Acta Biomater, 2010, 6: 1792-1799

16 Schumacher S, Stahl J, Bäumer W, et al. Ex vivo examination of the biocompatibility of biodegradable magnesium via microdialysis in the isolated perfused bovine udder model. Int J Artif Orgars, 2011, 34: $34-43$

17 Ulrich A, Ott N, Tournier-Fillon A, et al. Investigation of corrosion behavior of biodegradable magnesium alloys using an online-micro-flow capillary flow injection inductively coupled plasma mass spectrometry setup with electrochemical control. Spectrochim Acta Part B-Atomic Spectr, 2011, 66: 536-545

18 Zhao D, Wang T, Guo X, et al. Monitoring biodegradation of magnesium implants with sensors. JOM, 2016, 68: 1204-1208

19 Zhao D, Wang T, Kuhlmann J, et al. In vivo monitoring the biodegradation of magnesium alloys with an electrochemical $\mathrm{H}_{2}$ sensor. Acta Biomater, 2016, 36: 361-368

20 Zhao $\mathrm{D}$, Wang $\mathrm{T}$, Nahan $\mathrm{K}$, et al. In vivo characterization of magnesium alloy biodegradation using electrochemical $\mathrm{H}_{2}$ monitoring, ICP-MS, and XPS. Acta Biomater, 2017, 50: 556-565

21 Altura BT, Shirey TL, Young CC, et al. Characterization of a new ion selective electrode for ionized magnesium in whole blood, plasma, serum, and aqueous samples. Scandinavian J Clin Lab Invest, 1994, 54: 21-36

22 Günzel D, Schlue WR. Determination of $\left[\mathrm{Mg}^{2+}\right]^{i-}$ : an update on the use of $\mathrm{Mg}^{2+}$-selective electrodes. Biometals, 2002, 15: 237-249

23 Gáspár S, Wang X, Suzuki H, et al. Amperometric biosensor-based flow-through microdetector for microdialysis applications. Anal Chim Acta, 2004, 525: 75-82

24 Frost M, Meyerhoff ME. In vivo chemical sensors: tackling biocompatibility. Anal Chem, 2006, 78: 7370-7377

25 Ungerstedt U, Pycock C. Functional correlates of dopamine neurotransmission. Bulletin der Schweizerischen Akademie der Medizinischen Wissenschaften, 1974, 30: 44

26 Córcoles EP, Deeba S, Hanna GB, et al. Use of online rapid sampling microdialysis electrochemical biosensor for bowel anastomosis monitoring in swine model. Anal Methods, 2011, 3: 2010

27 Abrahamsson P, Aberg AM, Johansson G, et al. Detection of myocardial ischaemia using surface microdialysis on the beating heart. Clinical Physiol Funct Imag, 2011, 31: 175-181

28 Mortensen SP, Thaning P, Nyberg M, et al. Local release of ATP into the arterial inflow and venous drainage of human skeletal muscle: insight from ATP determination with the intravascular microdialysis technique. J Physiol, 2011, 589: 1847-1857

29 Feuerstein D, Manning A, Hashemi P, et al. Dynamic metabolic response to multiple spreading depolarizations in patients with acute brain injury: an online microdialysis study. J Cerebral Blood Flow Metabolism, 2010, 30: 1343-1355

30 Nilghaz A, Wicaksono DHB, Gustiono D, et al. Flexible microfluidic cloth-based analytical devices using a low-cost wax patterning technique. Lab Chip, 2012, 12: 209-218

31 Malon RSP, Chua KY, Wicaksono DHB, et al. Cotton fabric-based electrochemical device for lactate measurement in saliva. Analyst, 2014, 139: 3009-3016

32 Bagherbaigi S, Córcoles EP, Wicaksono DHB. Cotton fabric as an immobilization matrix for low-cost and quick colorimetric enzyme-linked immunosorbent assay (ELISA). Anal Methods, 2014, 6: 7175-7180

33 Compagnone D, Esti M, Messia MC, et al. Development of a biosensor for monitoring of glycerol during alcoholic fermentation. Biosens Bioelectron, 1998, 13: 875-880 
34 Emilia Ghica M, Brett CMA. Development and applications of a bienzymatic amperometric glycerol biosensor based on a poly (neutral red) modified carbon film electrode. Anal Lett, 2006, 39: 1527-1542

35 Zhao MC, Liu M, Song G, et al. Influence of the $\beta$-phase morphology on the corrosion of the Mg alloy AZ91. Corrosion Sci, 2008, 50: 1939-1953

36 Plock N, Kloft C. Microdialysis-theoretical background and recent implementation in applied life-sciences. Eur J Pharm Sci, 2005, 25: $1-24$

37 Wang $\mathrm{Y}$, Wei M, Gao J, et al. Corrosion process of pure magnesium in simulated body fluid. Mater Lett, 2008, 62: 2181-2184

38 Ghoneim AA, Fekry AM, Ameer MA. Electrochemical behavior of magnesium alloys as biodegradable materials in Hank's solution. Electrochim Acta, 2010, 55: 6028-6035
39 Tian Q, Deo M, Rivera-Castaneda L, et al. Cytocompatibility of magnesium alloys with human urothelial cells: a comparison of three culture methodologies. ACS Biomater Sci Eng, 2016, 2: 15591571

Acknowledgements This work was supported by the Malaysian Ministry of Education and the Natural Sciences and Engineering Research Council of Canada (NSERC).

Author contributions All authors contributed to the preparation and discussion of the manuscript. The final version of the manuscript was approved by all authors.

Conflict of interest The authors declare that they have no conflict of interest.
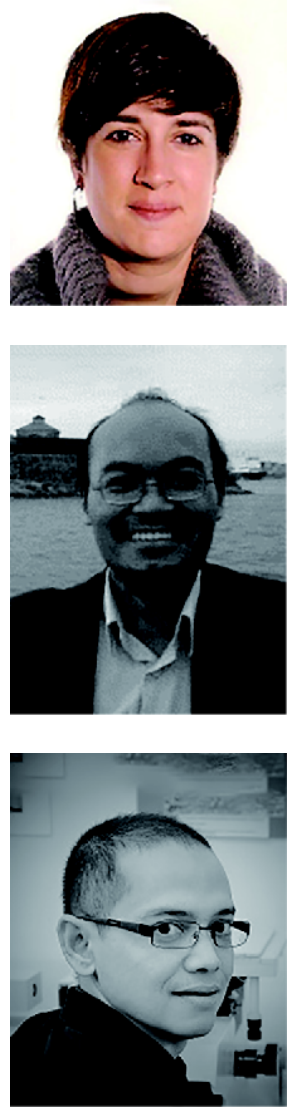

Emma Corcoles received her PhD degree in bioengineering from the Imperial College London in 2009. She is now working at the Instituto de Microelectrónica de Barcelona, Spain. Her research interests include electrochemical catalytic biosensors, immunosensors and other analytical techniques fabricated using different technologies and on different platforms and materials.

Dedy Wicaksono received his PhD degree in microelectronics from Delft University of Technology in 2008. He is now a lecturer at Swiss German University, Tangerang, Indonesia. His specialties include sensor and transducer design, physical modelling by analytical and numerical methods, characterization setup design and implementation, and device material process and characterization.

Hendra Hermawan received his $\mathrm{PhD}$ degree in materials engineering from Laval University in 2009. After spending some academic years in Asia, he returned to Laval University in 2014 as assistant professor and also researcher at CHU de Québec Research Center, Québec, Canada. His research interests include biomaterials, biodegradable metals and corrosion. 